\title{
Pathogenicity and rDNA-ITS sequence analysis of the Corynespora cassiicola isolates from rubber plantations in Indonesia
}

\author{
Fetrina Oktavia ${ }^{1 *}$, Kuswanhadi ${ }^{1}$, Widodo $^{2}$, Diny Dinarti ${ }^{3}$, Sudarsono ${ }^{3}$ \\ ${ }^{1}$ Sembawa Research Centre, Indonesian Rubber Research Institute, Palembang, Indonesia, ${ }^{2}$ Department of Plant Pathology, Bogor \\ Agricultural University, Dramaga, Bogor, Indonesia, ${ }^{3}$ Plant Molecular Biology Laboratory, Department of Agriculture, Bogor Agricultural \\ University, Dramaga, Bogor, Indonesia
}

\section{A B S T R A C T}

Corynespora cassiicola is an important pathogen causing Corynespora leaf fall disease on the rubber tree. Analysis of virulence and rDNAITS sequence were undertaken to investigate the effect of agro-climatic conditions and host rubber clones to virulence of 23 C. cassiicola isolates on six clones (RRIC 100, BPM 24, BPM 1, PB 260, GT 1 and RRIM 600) and to observed the evolution pattern of C. cassiicola isolates. Virulence analysis showed that there is an interaction between isolates and clones, indicating the differences of each isolates virulence to six clones. Agro-climatic conditions and host clones influenced the virulence of isolates and rDNA-ITS sequence variation. Analysis of rDNA-ITS showed that there were three of Single Nucleotide Polymorphism (SNP) that separated of isolates into 5 haplotypes. Most of the isolates belonging to the haplotype 1. Phylogenetic analysis indicated that $C$. cassiicola have a high diversity, however the clustering did not indicate country and host species of isolates. This information will be very useful on developing strategies of disease management and rubber plant breeding towards resistance to CLF disease.

Keywords: Cassiicolin; CLF disease; Genetic diversity; Hevea brasiliensis; rDNA-ITS

\section{INTRODUCTION}

Corynespora cassiicola is one of the most important plant pathogenic fungi that attacks a lot of plant species. The pathogen has wide range of host plants whrere it is found in more than 388 species (Farr and Rossman, 2015) including fruit, flower, vegetable, ornamental and perennial plants (Smith and Schlub, 2005; Furukawa et al., 2008; Shimomoto et al., 2008; Hieu et al., 2014). The fungus can attack all parts of plants such as leaves, roots, stems, fruits and flowers (Dixon et al., 2009).

In the rubber plant, C. cassiicola causes leaf fall disease, which has become one of the most important diseases of rubber in all of the natural rubber producing countries in Asia and Africa (Fernando et al., 2010; Ogbebor, 2010). In the country of origin of the rubber plant, Brazil, C. cassiicola is still found as an endophyte fungus and a potentially dangerous pathogen (Déon et al., 2012a). CLF disease can attack rubber plants at all stages of growth and development in both the nursery and in field plantation (Othman, 2013). It can cause severe damage and reduce the production of latex by about $60 \%$ and it can cause death of rubber plants (Situmorang et al., 2007).

Evolution process of the $C$. cassiicola was showed by the variation and changes of the isolates virulence level. The previous studies had reported influence of the origin of host species to pathogenicity pattern of the C. cassiicola isolates (Cutrim and Silva, 2003), where the different pathogenicity could be found on the isolates from the same host (Furukawa et al., 2008), or a isolates had a different pathogenic pattern to some species, pathogenic to one species but saprophytic to others depended on their host (Dixon et al., 2009; Shimomoto et al., 2011). Host specificity is not only found on the level of host species, but also at the lower genetic level that are rubber clones (Smith and Schlub, 2005; Fernando et al., 2009).

\footnotetext{
${ }^{*}$ Corresponding author:

Fetrina Oktavia, Sembawa Research Centre, Indonesian Rubber Research Institute, Palembang, Indonesia.

E-mail: fetrina_oktavia@yahoo.com
} 
Effect of geographical condition of the isolates origin to the virulence level is related to climate, temperature, humidity and radiation conditions. It could be indicated by the different attack of CLF disease at some areas, which the severe attacks of CLF were often found in the lowland areas with moderate rainfall. Futherore there were a different of resistant level of clone in many locations showing that there were a geographic effect on the virulence of $C$. cassiicola isolates attacking of these clones (Saha et al., 2002; Atan and Hamid, 2003; Silva et al., 2003). The genetic diversity among isolates had been reported by using various methods such as RAPD (Romruensukharom et al., 2005; Oktavia et al., 2011) and ISSR (Nghia et al., 2008; Qi et al., 2009; Munir et al., 2011). Although those methods had been able to show the genetic diversity in the isolate genome and grouping of the isolates based on genetic similarity, however the information obtained was still not able to explain which part that had been changed and their effect on isolates virulence. This was due to both methods were only able to detect the diversity randomly, and also the repeatability and the homology assessment of used techniques were still low (Isabel et al., 1999).

ITS-rDNA (Interspecific Transcript Spacer- ribosomal DNA) is the sequence with a repeat unit of the ribosomal genes that is frequently used for genome clustering of the fungi (Nilsson et al., 2009). ITS-rDNA sequence showed the variation of species (Ganley and Kobayashi, 2007) shown by the difference of length of sequences due to insertions or deletions (one or several bases) or as a result of nucleotide substitutions without altering the number of bases (Katoch et al., 2015). Moreover, the ITS-rDNA can be used as a marker in the process of evolution (Glass and Donaldson, 1995). Diversity analysis using the ITS-rDNA sequences to construct of phylogenetic tree of the C. cassiicola isolates had been reported (Saha et al., 2002; Atan and Hamid, 2003; Romruensukharom et al., 2005; Nghia et al., 2008; 2010; Qi et al., 2011; Déon et al., 2012b; Déon et al. 2014; Hieu et al. 2014; Shuib et al. 2015), and these results showed that the ITS was very useful in phylogenetic study and DNA barcoding.

As a country having largest rubber plantation area with different geographic conditions, Indonesia has a huge of genetic diversity of C. cassiicola isolates. However, the extent to which the nucleotide diversity and their influence to virulence changes of $C$. cassiicola that attack rubber plantations in Indonesia has not been reported. These information are very important to develop the disease management strategies such as identification of source of the resistance gene, prediction of the genetic breakdown and distribution of the resistant varieties (Rampersad et al, 2013). This study aimed to evaluate the virulence diversity of the $C$. cassiicola isolates to six tested clones, to evaluate the virulence diversity of the C. cassiicola isolates that come from different geographical area and host rubber clones, to evaluate the nucleotide diversity of the ITS-rDNA sequences of 23 C. cassiicola isolates and comparison made with the sequences in Genebank.

\section{MATERIALS AND METHODS}

\section{Isolates of $C$. cassiicola}

A total of 23 C. cassiicola isolates analyzed in this research consisted of two groups. The first group was of 6 isolates from GT1 clone grown in rubber plantation in Indonesia i.e. North Sumatera, Bengkulu, Jambi, Lampung, East Java, Central Java and East Kalimantan, and the second group was of 17 isolates collected from different rubber clones grown in Sembawa Research Centre, South Sumatera. The clones and origins of each isolates and also resistance level of host clone to CLF disease is showed on Table 1, whereas Fig. 1 shows the location of isolates collection.

All Isolates were from rubber leaves showing symptoms of CLF disease. Isolations were made using PDA medium that contained chloramphenicol $(0.05 \%)$. Isolation of single spore from 10 days old culture was done by drip the sterile distilled water into the culture and then the liquid of culture obtained was retrieved using a sterile pipette and spread evenly in the water agar medium. Identification of the presence of single spores in the media was done under a microscope by identifying spore of $C$. cassiicola isolates and marked positions of the spores in the media. Furthermore, the single spores was cultured on new PDA for futher analysis. Preparation of cultures derived from single spore were performed to ensure genetic uniformity.

\section{Production and application of toxin}

Production of toxin was conducted in $100 \mathrm{ml}$ Czapeck liquid medium. The media were inoculated with three mycelia plugs (5 $\mathrm{mm}$ in diameter) taken from 7-days old culture of the isolates. The cultures were incubated for 16 days at room temperature, filtered through Whatman No 1 filter paper, and then continued filtered through Millipore filters membrane (pore size was $0.22 \mu \mathrm{m}$ ). The culture filtrate was used as the source of toxin.

\section{Pathogenicity analysis}

Pathogenicity tests of $C$. cassiicola isolates was done based on toxin activity of isolates on 6 test rubber clones leaves i.e. RRIC 100, BPM 24, BPM 1, PB 260, GT 1 and RRIM 600. The experiment was arranged in a completely randomized design with three replications for each isolate and every unit of treatment consisted of three young leaves (copper brown to green/B2C stage). 
Table 1: Host rubber clones, resistance level of hosts to $C$. cassiicola, geographic origins and genebank accession numbers of 23 C.cassiicola isolates that isolated from rubber plantation in Indonesia

\begin{tabular}{|c|c|c|c|c|}
\hline CC Isolate & Host clone & Resistance level of Host to $\mathrm{CC}^{\mathrm{a}}$ & Geographic origin $^{b}$ & GeneBank accession number \\
\hline CC-01 & GT 1 & Very susceptible & North Sumatera & KP759967 \\
\hline CC-02 & GT 1 & Susceptible & Bengkulu & KP759968 \\
\hline CC-03 & GT 1 & Very susceptible & Jambi & KP759969 \\
\hline CC-04 & GT 1 & Susceptible & Central Java & KP759970 \\
\hline CC-05 & GT 1 & Very susceptible & West Kalimantan & KP759971 \\
\hline CC-06 & GT 1 & Susceptible & South Sumatera & KP759972 \\
\hline CC-07 & IRR 32 & Very susceptible & South Sumatera & KP759973 \\
\hline CC-08 & IRR 72 & Susceptible & South Sumatera & KP759974 \\
\hline CC-09 & IRR 104 & Resistance & South Sumatera & KP759975 \\
\hline CC-10 & IRR 105 & Very resistance & South Sumatera & KP759976 \\
\hline $\mathrm{CC}-11$ & IRR 107 & Susceptible & South Sumatera & KP759977 \\
\hline CC-12 & IRR 112 & Resistance & South Sumatera & KP759978 \\
\hline $\mathrm{CC}-13$ & IRR 118 & Susceptible & South Sumatera & KP759979 \\
\hline $\mathrm{CC}-14$ & LCB 1320 & Susceptible & South Sumatera & KP759980 \\
\hline CC-15 & PB 217 & Resistance & South Sumatera & KP759981 \\
\hline CC-16 & PB 260 & Resistance & South Sumatera & KP759982 \\
\hline $\mathrm{CC}-17$ & PB 330 & Susceptible & South Sumatera & KP759983 \\
\hline CC-18 & PR 261 & Resistance & South Sumatera & KP759984 \\
\hline CC-19 & PR 300 & Resistance & South Sumatera & KP759985 \\
\hline CC-20 & PR 303 & Resistance & South Sumatera & KP759986 \\
\hline CC-21 & RRIC 100 & Very resistance & South Sumatera & KP759987 \\
\hline CC-22 & RRIM 600 & Very susceptible & South Sumatera & KP759988 \\
\hline CC-23 & TJIR 1 & Very susceptible & South Sumatera & KP759989 \\
\hline
\end{tabular}

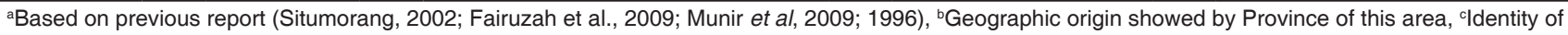
rDNA-ITS sequence of 23 C. cassiicola isolates from GeneBank



Fig 1. Map of Indonesia showing the locations of rubber plantations where the $C$. cassiicola isolates were collected. This locations indicated by the name of the Provinces this area. Insert is map of the world and position of Indonesia in this map.

Pathogenicity assay was performed according to the method described by Breton et al., (2000) with modifications. Three young leaves of each clone were collected from field and immersed in water for one night. Then, $125 \mathrm{ml}$ of toxin filtrate were placed in the chamber and covered by Styrofoam with holes having a diameter of $3 \mathrm{~cm}$. The petioles of excised leaves were placed into holes immersed in the toxin filtrate. Petioles of control leaves were immersed in the sterilized water. The leaves were incubated at room temperature under $100 \% \mathrm{RH}$. Observations were recorded for 48 hours after the incubation.

Pathogenicity or virulence of isolates was quantified based on the leaf water loss caused by toxin activity where observation was made after 48 hour immersion in toxin filtrate. The isolates virulence were grouped into weak, medium, high and extremely virulent based on the Standard Deviation (SD) value i.e. those which have a value under -1 
SD were grouped as weak virulence between $-1 \mathrm{SD}$ to mean as medium virulence, mean to $+1 \mathrm{SD}$ as high virulence, and more than $+1 \mathrm{SD}$ as a extremely virulent isolate.

The clustering of isolates based on the leaf wilting intensity on the each tester rubber clones had been done using the Euclidean Hierarchical clustering method by using the Darwin6 software (Perrier and Jacquemoud-Collet, 2010). Interaction of $C$. cassiicola isolates and clones test were analyzed using two factors ANOVA (isolate*clone) by SAS (Statistical Analysis System) program and differences between means were tested using DMRT (Duncan's Multiple Range Test) test $(\mathrm{P}<0.05)$.

\section{DNA extraction}

Fungal isolates were grown by placing 3 mycelia plugs into Erlenmeyer flaks containing $100 \mathrm{ml}$ Potato Dextrose Broth, isolates were shaken at $60 \mathrm{rpm}$ using an orbital shaker at room temperature for 10 days. The mycelia were collected and washed with distilled water and they were used for DNA extraction (Nghia et al., 2008). The concentration and purity of DNA was measured using spectrophotometer. The DNA was stored in the refrigerator at $4^{\circ} \mathrm{C}$ and it was used as stock for DNA template $(50 \mathrm{ng} / \mu \mathrm{l})$.

\section{Phylogenetic analysis based on ITS-rDNA sequence}

Identification of the 23 isolates of $C$. cassiicola from different rubber clones and different geographical regions were done using the ribosomal DNA Internal Transcribes Spacer (rDNA-ITS) region sequence. A region of the rDNA-ITS included the spacer between the $18 \mathrm{~S}$ and 5.8S rDNA subunits (ITS 1), the 5.8S rDNA subunit and spacer between the $5.8 \mathrm{~S}$ and $28 \mathrm{~S}$ rDNA subunits (ITS 2). The PCR was done using universal primers ITS1F (5'CTTGGTCATTTAGAGGAAGTAA3') and ITS4 (5'TCCTCCGCT'TATTGATATGC3') (White et al., 1990). The primers were synthesized at Integrated DNA Technologies (IDT) ${ }^{\circledR}$ Singapore.

PCR reactions were carried out in a volume of $25 \mu \mathrm{l}$ containing 1x PCR buffer, $0.2 \mathrm{mM}$ of dNTP mix, $2 \mathrm{mM}$ of $\mathrm{MgCl}_{2}, 0.5 \mathrm{U}$ of Taq polymerase (Kapa Biosystems ${ }^{\mathrm{TM}}$ Inc. USA), $0.2 \mu \mathrm{M}$ of primers, $50 \mathrm{ng}$ of DNA template and the final volume was adjusted to $25 \mu \mathrm{l}$ with nuclease free water. Amplifications were performed in a T-100 Thermal Cycler Bio-Rad ${ }^{\mathrm{TM}}$ that was programmed for initial denaturation at $95^{\circ} \mathrm{C}$ for $3 \mathrm{~min}$, followed by 35 cycles at denaturing temperature $95^{\circ} \mathrm{C}$ for $15 \mathrm{~s}$, annealing temperature $54^{\circ} \mathrm{C}$ for $15 \mathrm{~s}$, extention temperature $72^{\circ} \mathrm{C}$ for $30 \mathrm{~s}$ and final extention at $72^{\circ} \mathrm{C}$ for $3 \mathrm{~min}$. All PCR reactions were done in three technical replications. Amplified DNA fragment was confirmed using agarose gel electrophoresis containing of GelRed ${ }^{\mathrm{TM}}$ by running of $2 \mu \mathrm{l}$ PCR product on $1 \%$ agarose gel using 1xTAE buffer ( $40 \mathrm{mM}$ Tris, $20 \mathrm{mM}$ acetic acid and $1 \mathrm{mM}$ EDTA) at $60 \mathrm{~V}$ for $60 \mathrm{~min}$. The gel was visualized under Bio-Rad Gel Doc ${ }^{\mathrm{TM}}$ UV-Transluminator. The amplified DNA fragment size was estimated using $1 \mathrm{~kb}$ DNA ladder marker (Vivantis). The PCR products were sequenced by a commercial sequencing service (First BASE Laboratories Sdn. Bhd. Malaysia) by using the ITS1F and ITS4 primers. Sequencing were based on Sanger's dideoxy sequencing technology with Big Dye Terminator v3.1 cycle sequencing kit chemistry (Applied Bio systems).

The sequence data of isolates were refined using Geneious Pro Trial software (version 5.6.6) (Drummond et al., 2012) in which the sequence from reverse primer of ITS4 was transformed to reverse complement and they were aligned with the sequence from forward primer of ITS1F for correcting of the ambiguous nucleotides on analyzed chromatogram. The species identity of the 23 isolates were confirmed by analyzing these sequences using the BLAST alignment. The sequence data obtained were submitted to GenBank with accession number listed in Table 1. Analysis of isolates clustering based on ITS-rDNA sequences was performed by the Neighbour-Joining method with number of bootstrap of 1000 using Mega6 program (Tamura et al., 2013), whereas to detect the similarity among C. cassiicola isolates and with other isolates that deposit in Gene Bank database, all sequences were allignmented and done the phyllogenetic tree analysis using Neighbour-Joining (NJ) methods with 1000 bootstrap by Geneious Pro Trial software (version 5.6.6). List of accessesion number, the host clones and region of origin of $C$. cassiicola isolates can be seen in Table 2. Identification of haplotypes based on mutation of the nucleotide bases was done by using algorithms Reduced Median of Network v 4.6.1.1 software (Bandelt et al., 1999).

\section{RESULTS}

\section{Pathogenicity analysis}

Pathogenicity analysis was based on the leaf water loss estimation caused by toxin activity from 23 C. cassiicola isolates on the six tested rubber clones (BPM 1, BPM 24, GT 1, PB 260, RRIC 100 and RRIM 600). Result of two factor of ANOVA (isolate*clone) and DMRT test $(\mathrm{P}<0.05)$ showed that there were a significant effect of the isolate and clone factors to pathogenicity of $C$. cassiicola. DNMRT test $(\mathrm{P}<0.05 \%)$ showed that each of the C. cassiicola isolates had different virulence level on each tested rubber clones (Data not shown).

Virulence level of the 23 isolates was recorded for 6 Hevea clones (Table 3). Each isolate had a different virulence activity on the 6 clones. However, some isolates could be classified as strong or weak virulent when most of clones 
Table 2: Accession numbers, hosts species and origin of countries of $C$. cassiicola isolates using in phylogenetic analysis of the ITS-rDNA sequences

\begin{tabular}{|c|c|c|c|}
\hline Genes & Origin of country & Host species & Accession number \\
\hline \multirow[t]{27}{*}{ ITS-rDNA } & \multirow[t]{2}{*}{ Malaysia } & H. brasiliensis & EU364535, EU364547, EU364551, EU364552, EU364555 \\
\hline & & M. minifera & KM510384 \\
\hline & \multirow[t]{6}{*}{ China } & H. brasiliensis & EF198115, EU822317, EU131376, EU935735, EU822314, EU822315 \\
\hline & & C. satisvus & EF198116, EF198117 \\
\hline & & C. papaya & EU735060, EU735064 \\
\hline & & A.chinensis & KJ747095 \\
\hline & & G.bardense & KF924624 \\
\hline & & B. cusia & JX908713 \\
\hline & India & H. brasiliensis & EF471932 \\
\hline & \multirow[t]{2}{*}{ South Korea } & C. sativus & AY238605, AY238606 \\
\hline & & C. annum & KM107809 \\
\hline & Japan & C. annum & AB366651, AB366652 \\
\hline & \multirow[t]{7}{*}{ Brazil } & H. brasiliensis & HQ641074 \\
\hline & & Perilla $s p$ & HQ641081 \\
\hline & & G. $\max$ & HQ641076, HQ641077, HQ641080 \\
\hline & & C. papaya & HQ641075 \\
\hline & & C. sativus & HQ641073, HQ641079 \\
\hline & & P. barbatus & HQ641078 \\
\hline & & C. benghalensis & HQ641071 \\
\hline & \multirow[t]{7}{*}{ Vietnam } & H. brasiliensis & $\begin{array}{l}\text { KF387614, KF387610, KF387609, KF387606, KF387605, KF387603, KF387602, } \\
\text { KF387600, KF387599, KF387598, KF387597, KF387596, KF387595, KF387591 }\end{array}$ \\
\hline & & C. papaya & KF387608, KF387607, KF387604, \\
\hline & & S. indicum & KF387601, \\
\hline & & B. hispida & KF387594 \\
\hline & & U.rosea & KF387593 \\
\hline & & I. malayana & KF387592 \\
\hline & & L. esculenta & KF266787, KC138855 \\
\hline & Indonesia & H. brasiliensis & $\begin{array}{l}\text { KP759967, KP759968, KP759969, KP759970, KP759971, KP759972, } \\
\text { KP759973, KP759974, KP759975, KP759976, KP759977, KP759978, } \\
\text { KP759979, KP759980, KP759981, KP759982, KP759983, KP759984, } \\
\text { KP759985, KP759986, KP759987, KP759988, KP759989 }\end{array}$ \\
\hline
\end{tabular}

had a similar pattern. The influence of geographical areas and host clones were analyzed by clustering analysis of isolates using Hierarchy Euclidean method based on the leaf wilting intensity on the each of clone tester (Fig. 2). Isolates from different regions and host clones were distributed in different groups. There were three clusters of isolates. The first cluster was dominated by isolates from the same clone, furthermore the second and third cluster consisted of isolates from different clones. This result led to conclusion that isolates from different clones were more widespread than isolates from the same clone, or virulence diversity caused by the influence of the host clones were greater than the influence of the geographical areas.

Acording to the average of virulence on the six clones tested, CC-20, CC-22 and CC-23 isolates were the highest virulence isolates (Table 3 ), and then the clustering analyzes showed that all the three isolates grouped into the third group separate from the others (Fig. 2).

Clustering of virulence level based on Standard Deviation (SD) of leaf wilting intensity which under of -1 SD was classified as avirulent isolates, between $-1 \mathrm{SD}$ to average was weakly virulent, betwen average to $+1 \mathrm{SD}$ was strongly virulent and more than +1 SD was classified as a extremely virulent isolates.

CC-01 to CC-06 isolates were collected from GT 1 clones from different area, CC-07 to CC-23 isolates were collected from different clones from the same area.

BPM 1 and RRIC 100 were very resistant, BPM 24 and PB 260 moderately resistant and GT 1 and RRIM 600 susceptible to CLF disease

\section{Phylogenetic analysis based on rDNA- ITS sequence} PCR amplification of total genomic DNA of 23 C. cassiicola isolates using the ITS $1 \mathrm{~F}$ and ITS 4 primers obtained a single DNA fragment in equal size (559 bp). According to BLAST with other sequence of $C$. cassiicola isolates in GeneBank of National Centre for Biotechnology Information (NCBI) showed that the sequences similarity among these isolates was $99-100 \%$ and between these isolates with C. cassiicola sequences in NCBI was $97-100 \%$. Moreover, BLAST 
Table 3: Clustering of virulence level of 23 C. cassiicola isolates based on leaf wilting intensity on each and average to six test rubber clones which have a different resistance to CLF disease

\begin{tabular}{|c|c|c|c|c|c|c|c|}
\hline \multirow[t]{2}{*}{ CC Isolates } & \multicolumn{6}{|c|}{ Cluster of virulence on test rubber clones } & \multirow[t]{2}{*}{ Average to all test clones } \\
\hline & BPM1 & RRIC100 & BPM24 & PB260 & GT1 & RRIM600 & \\
\hline $\mathrm{CC}-01$ & Weak $^{\mathrm{a}}$ & Extreme & Avirulent & Weak & Extreme & Strong ${ }^{b}$ & Strong \\
\hline CC-02 & Avirulent & Strong & Strong & Strong & Extreme $^{c}$ & Strong & Strong \\
\hline CC-03 & Weak & Extreme & Avirulent & Strong & Strong & Weak & Strong \\
\hline CC-04 & Avirulent & Extreme & Weak & Strong & Strong & Extreme & Strong \\
\hline CC-05 & Weak & Strong & Strong & Weak & Extreme & Strong & Strong \\
\hline CC-06 & Weak & Extreme & Strong & Strong & Strong & Strong & Strong \\
\hline CC-07 & Strong & Weak & Weak & Strong & Extreme & Weak & Strong \\
\hline CC-08 & Weak & Weak & Avirulent & Weak & Weak & Avirulent & Weak \\
\hline CC-09 & Strong & Strong & Weak & Strong & Weak & Strong & Strong \\
\hline CC-10 & Weak & Strong & Weak & Weak & Avirulent & Weak & Weak \\
\hline CC-11 & Avirulent & Weak & Weak & Weak & Weak & Avirulent & Weak \\
\hline CC-12 & Strong & Weak & Avirulent & Strong & Extreme & Weak & Strong \\
\hline $\mathrm{CC}-13$ & Avirulent & Strong & Avirulent & Weak & Weak & Weak & Weak \\
\hline CC-14 & Strong & Strong & Strong & Strong & Weak & Extrem & Strong \\
\hline CC-15 & Avirulent & Strong & Avirulent & Strong & Avirulent & Weak & Weak \\
\hline CC-16 & Weak & Extreme & Weak & Strong & Weak & Strong & Strong \\
\hline CC-17 & Strong & Weak & Weak & Strong & Weak & Weak & Weak \\
\hline CC-18 & Strong & Strong & Weak & Strong & Strong & Avirulent & Strong \\
\hline CC-19 & Weak & Weak & Weak & Weak & Avirulent & Avirulent & Weak \\
\hline CC-20 & Weak & Weak & Strong & Extreme & Extreme & Extreme & Extreme \\
\hline CC-21 & Strong & Avirulent & Weak & Weak & Avirulent & Weak & Weak \\
\hline CC-22 & Weak & Weak & Extreme & Strong & Extreme & Extreme & Extreme \\
\hline CC-23 & Weak & Strong & Extreme & Extreme & Strong & Extreme & Extreme \\
\hline
\end{tabular}

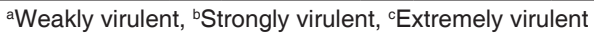



Fig 2. Euclidean Hierarchical clustering method of 23 C. cassiicola isolates based on leaf wilting intensity on the six rubber clones (BPM 1, RRIC 100, BPM 24, PB 260, GT 1 and RRIM 600) which have a different resistance level to CLF disease.

analysis also showed that this fragment was part of ITS (Interspecific Transcript Spacer) 1 sequence, complete sequence of $5.8 \mathrm{~S}$ rDNA and part of ITS 2 sequence.

Phylogenetic analysis using the Neighbour Joining method showed that there was a broad of genetic diversity of the isolates from Indonesia. Isolates could be classified into two large groups. The largest groups could be divided into a smaller subgroups. Most of the isolates were classified into the first large group, which one of this group was divided into two small groups. Likewise, the second major group were split in to two small groups (Fig. 3). The grouping 
did not show the position closely of the geographical and the virulence level of isolates. Based on the geographical area, the isolates from the GT1 clones grouped separately on the some small groups and then almost of all isolates belonging to the first major group except the isolate from North Sumatera.

Despite having an average similar capability of virulence to six test clones, but the genetically that showed by grouping on the phylogenetic tree were not determined by the closeness of geographically origin of isolates. Geographically, North Sumatera, Jambi, Bengkulu and South Sumatera are located in one of island, while Central Java and West Kalimantan are on the different islands, but in the phylogenetic tree showed that isolate from Bengkulu was in the separate group, while Jambi, Central Java and South Sumatera isolates merged in the same group, as well as North Sumatera and West Kalimantan isolates merged in the other group (Fig. 1 and 3).

The alignment analysis of $23 \mathrm{rDNA}-\mathrm{ITS}$ sequences of C. cassiicola showed that almost all of the sequences were identical, except three points of SNPs (Single Nucleotide Polymorphism) in different positions, namely at nucleotide $98^{\text {th }}(\mathrm{C} / \mathrm{T}), 133^{\text {th }}(\mathrm{T} / \mathrm{C})$ and $549^{\text {th }}(\mathrm{A} / \mathrm{G})$. All of SNPs were used as a basis on the network analysis using Reduced Median method that indicated a distance and a pattern of the positions change of mutated nucleotides, either directly into haplotypes or through several of mutations stages.

Based on the mutation patterns of nucleotide bases there were five haplotypes of the C. Cassiicola isolates. The isolates changed from progenitor of haplotype 1 to haplotype 2 through mutation of $549^{\text {th }}$ nucleotide base which altered A to G. Likewise with haplotype 3 that changes of the $98^{\text {th }}$ base from $\mathrm{T}$ to $\mathrm{C}$ and on the haplotype 5 there was a mutation at the base $133^{\text {rd }}$ that converts $\mathrm{C}$ to $\mathrm{T}$. in the other hand, haplotype 4 have two of base mutation namely the $133^{\text {rd }}$ that convert of $\mathrm{C}$ to $\mathrm{T}$ and $549^{\text {th }}$ base that convert A to $\mathrm{G}$. Each hapotype had a different frequency that determined by population size. From all haplotypes, haplotype 1 was the highest frequency, $52.2 \%$ (Fig. 4 and Table 4). The fig. 4 also showed that the Indonesian's isolates have a 5-7 differences of nucleotide mutation point with other countries isolates (outgroup).

Isolates were classified in different haplotypes using the differences of mutation point (Table 4). There was a close relationship between virulence level of isolates with geographically origin of isolates that showed by isolates virulence to the host clone (GT 1) (Table 3). Isolates from Jambi, South Sumatera and Central Java which have a haplotypes sequence TCA and in the same phylogenetic group, have the same virulence level (high virulence) to

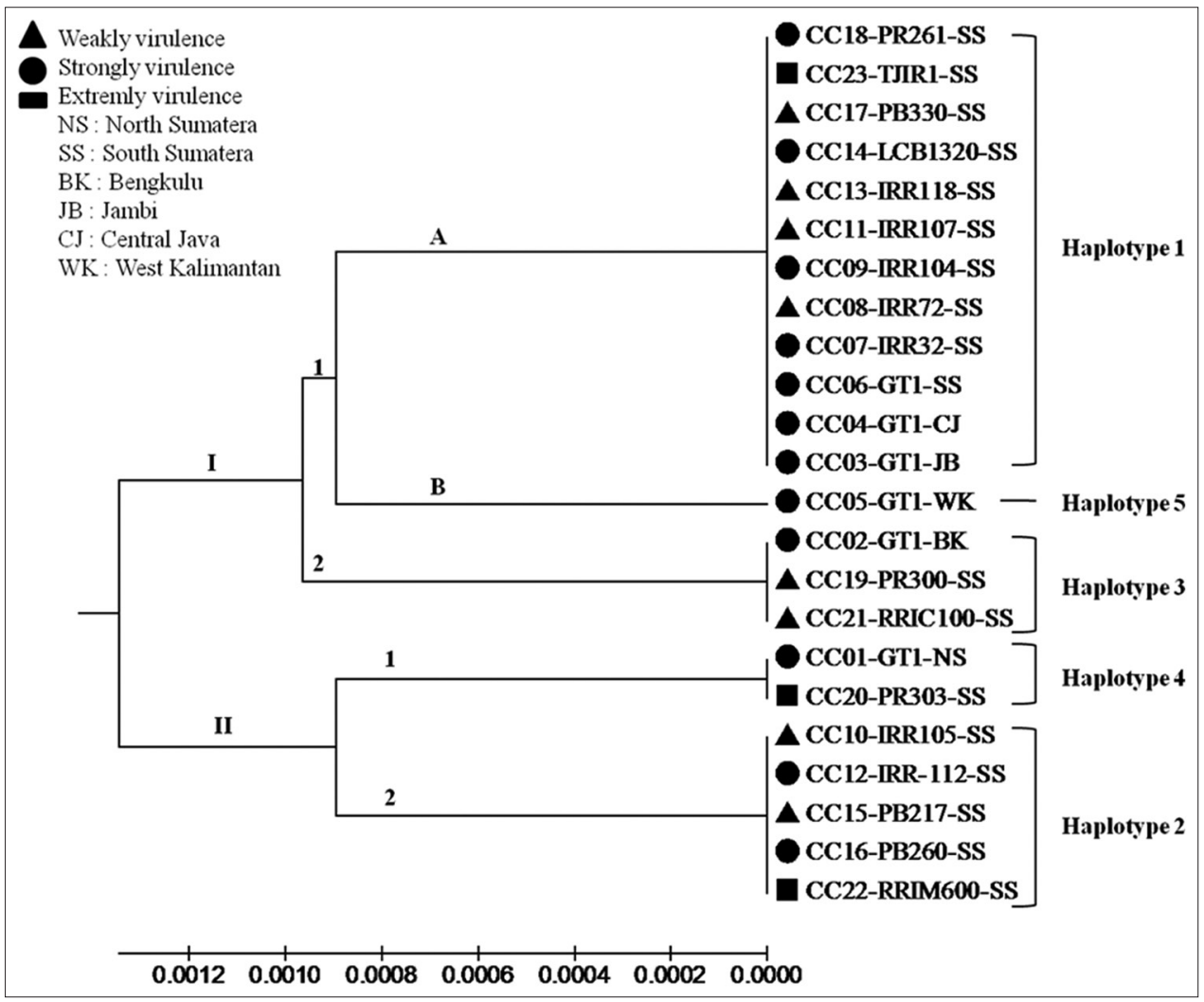

Fig 3. Phyllogenetic analysis of 23 C. cassiicola isolates of different host rubber clones and geographic origins. The tree was generated from the ITS-rDNA dataset using the Neighbour-Joining (NJ) method. The haplotypes and virulence types of isolates were also indicated. 
the host plant. But when there was a mutation in one of these bases, level of virulence would turn out to be very virulent. These were showed by isolate from Bengkulu that had haplotype sequence of CCA and isolate from West Kalimantan that had a haplotype sequence of CTA. While in isolate from North Sumatera, there were two bases mutation, namely $\mathrm{C}$ replaced by $\mathrm{T}$ and $\mathrm{A}$ by $\mathrm{G}$ thus haplotype bases of TTG. It was indicated that there was genetic variation in isolates that come from a different geographic that would affect the virulence level of isolates.

Effect of mutations on the virulence level of isolates was also shown by the changes over time as reflected also from changes of the resistance level of the host plant. A previous study reported that GT1 had the resistance level of a medium-susceptible to $C$. cassiicola isolates meaning that the isolates had a high level of virulence. Nevertheless the isolates from North Sumatera, Bengkulu and West Kalimantan that had different mutation point with Jambi, South Sumatera and Central Java, the level of virulence change were from high become very virulent (Table 3).

In the other hand, type of host rubber clones showed the genetic diversity of isolates that indicated by isolates grouped into different groups and haplotypes. Haplotype sequence analysis of each isolate indicated that there was a change of the nucleotide base to 98 from $\mathrm{T}$ to $\mathrm{C}$ and

Table 4: Haplotype sequences and frequencies of 23 C. cassiicola isolates from Indonesia based on ITS-rDNA sequences

\begin{tabular}{llcc}
\hline Haplotypes & Sequences & Frequency & Number of Isolates \\
\hline Haplotype 1 & TCA & 52.2 & 12 \\
Haplotype 2 & TCG & 21.7 & 5 \\
Haplotype 3 & CCA & 13.0 & 3 \\
Haplotype 4 & TTG & 8.7 & 2 \\
Haplotype 5 & TTA & 4.4 & 1 \\
\hline
\end{tabular}

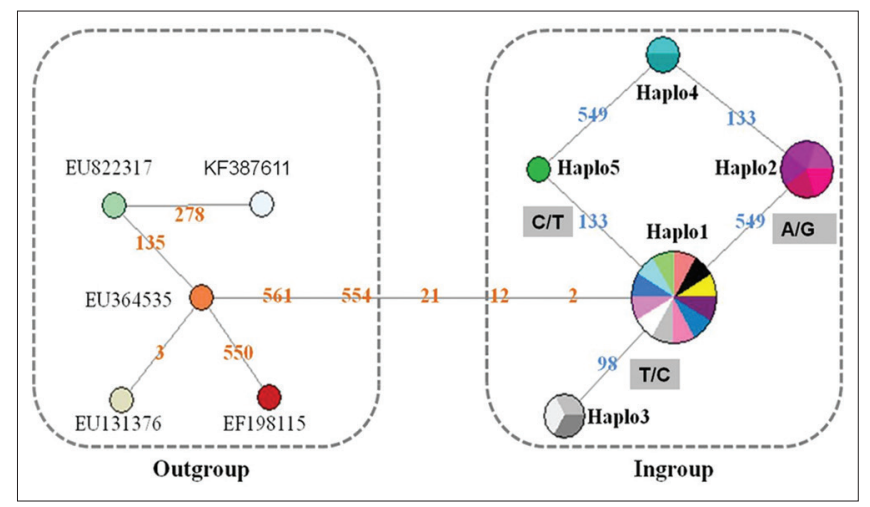

Fig 4. Haplotypes network based on Reduced Median from ITS-rDNA sequences of $23 \mathrm{C}$. cassiicola isolates from Indonesia and other countries (EU364535 from Malaysia, EU131376, EF198115 and EU822317 from China, KF387611 from Vietnam). Haplotype colour represent the isolates member of the haplotype. Number in the line of network represent the nucleotide mutation position of ITS-rDNA sequences. base to 549 from A to $G$ in some of isolates. Although mutations in these bases were slightly shifting the level of the isolates virulence, but it have not been able to show a close relationship between changes in the ITS-rDNA sequences with altered levels of isolates virulence.

The phylogenetic analysis depicts the genetic diversity of the C. cassiicola isolates from different plant species and from various countries based on ITS-rDNA gene sequences (Fig. 5). The phylogenetic tree showed that the isolates from Indonesia are in the same group along with many of the sequences from the database. There were two groups of Indonesian isolates, of which 20 isolates were joined by the large group of sequences databases, and only three isolates joined with other. Nevertheless, the grouping was at random based on similarity of ITS-rDNA sequences not on host species and regions of origin.

\section{DISCUSSION}

Diversity of $C$. cassiicola races could be determined by the pathogenicity level. This information is useful to identify species and races of $C$. cassiicola isolates, and for the selection of management strategies to protect and control disease spreading in rubber plantations. The pathogenicity test was performed using a toxin assay method by considering that cassiicolin toxin produced by $C$. cassiicola was a main effector in the pathogenicity process of $C$. cassiicola isolate (Breton et al., 2000; de Lamotte et al., 2007; Déon et al., 2012b; Déon et al., 2014). In addition, Tran et al. (2016) reported that there were six QTL (Quantitative Trait Loci) linked to sensitivity to toxin filtrate of $C$. cassiicola detected on five chromosomes of rubber plant, suggesting that cassiicolin is the main effector in pathogenicity. Using of the toxin filtrate of phytoptahogenic as a selection tool has also been reported on several pathogen such as Sclerotium rolfsii (Yusnita et al., 2009), Phytophthora parasitica (Savita et al., 2011) and Fusarium oxysporum (Oubraim et al., 2016). It caused that the detection of virulence may be more emphased on the genetic factors and minimizing the influence of environmental factors.

Each C. cassiicola isolates has a different of virulence level. This indicated that there is a specific interaction between pathogen with the host clones and there is the environmental impact to the virulence ability of isolate. This effect is related to temperature, humidity, rainfall and sun light that will affect the production and development of C. Cassiicola isolates (Fernando et al., 2012).

All of isolates were virulent, although some isolates were avirulent to a few of tested clones. But this is a reasonable because the tested clones are not a host clones origin of 


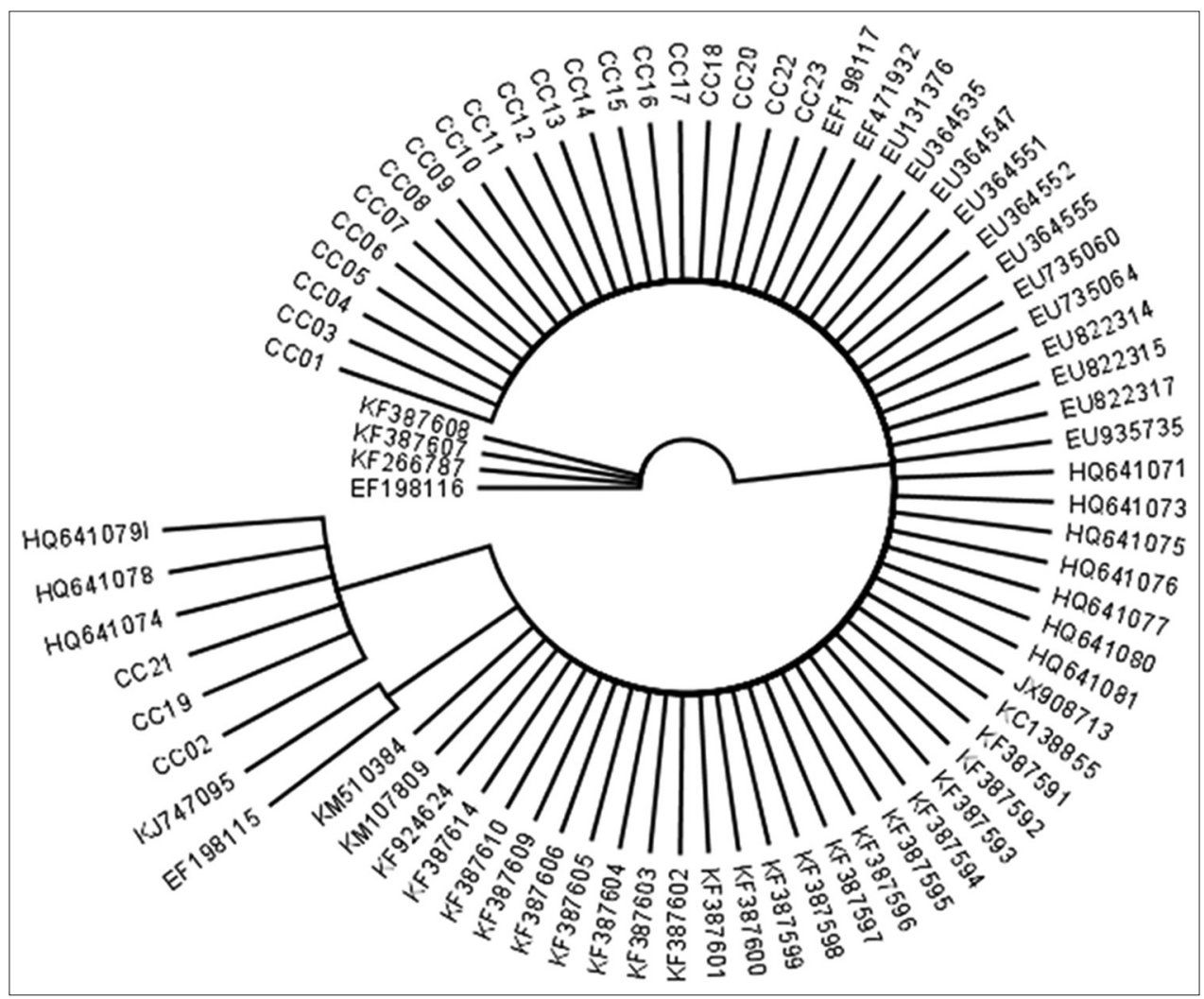

Fig 5. Phylogenetic tree of 23 C. cassiicola isolates from Indonesia (CC-01 to CC-23) and other countries from database based on ITS-rDNA sequences using the Neighbor-Joining (NJ) method.

the isolates. Basically the isolates is virulent because it was isolated from the leaf tissue have CLF symptoms. This is consistent with previous research which reported that C. cassiicola isolate is able to attack all rubber clones with different levels of severity (Akpaja et al., 2015). There were 3 of C. cassiicola isolates namely CC-20, CC-22 and CC-23 that isolated from PR 303, RRIM 600 and Tjir 1 rubber clone which very virulent, so all the isolates must be wary because it could be very dangerous to the rubber plantation.

The study of correlation between virulence of C. Cassiicola isolates with different host species showed that there were a differences of isolates virulence to the plants which most of isolates isolated from different host species had a huge broad host range and most others had a specific host (Pereira et al. 2003; Nilsson et al., 2009; Shimomoto et al., 2011; Schoch et al., 2012; Glass et al., 2013). The same case was also found in this study, where the isolates from different rubber clones showed a different of virulence level to six of tested clones. Their specificity of virulence capability is expected to link to the main effectors of pathogenicity on the C. Cassiicola that is namely cassiicollin. It is a Host Specific Toxin (HST), so that there is a relationship of gene for gene between Avr gene of isolates with $\mathrm{R}$ gene of host plant (Gururani et al., 2011). Furthermore the virulence level of an isolate is also influenced by the resistance level of plants infected, either through the mechanism of toxin degradation or other defense mechanisms that caused plant cell walls become less sensitive to the toxins was released by isolates (Déon et al., 2012b; Déon et al., 2014).

A variety of other genes classified as house-keeping genes such as $A c t, G A 4, g p d$, tefl, CAA and ITS-rDNA may be used in the identification and clustering of C. cassiicola isolates (Dixon et al., 2009; Gazis et al., 2011; Shimomoto et al., 2011; Déon et al., 2014). Among of these genes, ITS-rDNA genes were considered capable of well classifying the $C$. cassiicola isolates based on genetic relatedness (Dixon et al., 2009; Shimomoto et al., 2011). It has been chosen in the diversity analysis of fungi with consider that these primers are universal (Nilsson et al., 2008) and the sequence information is already in the database. Furthermore these sequences can also be used as an early selection of isolates by the grouping that may be used on the resistance test of the new clones in the rubber breeding program.

There were 3 SNPs on the ITS-rDNA sequences of C. cassiicola isolates indicated that there have been a transition mutation in the isolates genome, that is replacement of the one base in the same class, purine is replaced by the purine and pyrimidine replaced by pyrimidine (Primmer et al., 2002). Commonly, the frequency of transition mutations 
in the genome is higher than transversion mutations (replacement of bases from different classes) (Yang et al., 2004; Zeng et al., 2009), because these bases have the balance structure of the backbone of the constituent DNA bases (Guo and Jamison 2005).

Qi et al. (2011) reported that the fragment size of the rDNA of C. cassiicola isolates that successfully amplified using the ITS primer was $180 \mathrm{bp}, 158 \mathrm{bp}$ and $221 \mathrm{bp}$ for ITS-1, 5.8S and ITS-2 respectively, so the first (base to-98) and the second (base to-133) of SNP position were expected on the ITS 1 sequence, the third SNP (base to-549) on the ITS 2 sequence, while the $5.8 \mathrm{~S}$ subunit conserve to all of isolates. These results are consistent with a previous study which state that $5.8 \mathrm{~S}$ subunit on the rDNA gene are a region conserve in all organisms and ITS regions are a high diversity so it can be used on the identification of a species, genetic diversity analysis, DNA barcoding and analysis of fungi phylogenetic (Hinrikson et al., 2005; Murali et al., 2006; Nilsson et al., 2009; U'ren et al., 2009; Schoch et al., 2012; Glass et al., 2013; Harrington et al., 2014), as well as a locus supports the clustering of C. cassiicola isolates based on genetic similarity (Dixon et al., 2009). The differences of the SNPs positions of two ITS sequences in this study showed that the ITS 1 has a higher genetic variation than the ITS 2. It was estimated randomly mutation on genome of isolates. This is similar with previous study that stated ITS 1 sequence more variable than ITS 2 (Nilsson et al., 2009), whereas the other studies reported that the ITS 2 was better in detecting of the genetic variation in the closely related (Schoch et al., 2012).

All of SNP positions were an informative character in the analysis of genetic variation, where the SNP position can be used as a tool in determining of haplotypes (Dixon et al., 2009) or race group of C. cassiicola isolates (Nghia et al., 2010). Except of the third SNP position, the same SNP position were also found on the some of C. cassiicola isolates from other countries (Dixon et al., 2009; Nghia et al., 2010; Hieu et al., 2014). Network analysis based on Reduced Median method that showed the distance and the change pattern of the nucleotide positions mutated, either directly into the haplotypes or through several stages of mutations demonstrated that the isolates from Indonesia had a different genetic variations with other countries. Based on third of the SNPs, the Indonesian isolates were divided into five haplotypes separated by 1-2 point mutations and different frequency, where the highest frequency was found in the haplotype 1. These results indicated that there were at least five of different races in C. Cassiicola isolates from the rubber plant in Indonesia and most of the isolates were belonged to the race 1 .

\section{CONCLUSION}

Virulence analysis showed that there are a different of virulence levels of $C$. cassiicola isolates to six of tested rubber clones. The diversity analysis of ITS-rDNA sequence was known that there was a diversity of ITS-rDNA sequences of the 23 isolates of C. cassiicola analyzed and phylogenetic analysis of 23 isolates with ITS-rDNA sequence database shows that there was a high genetic diversity in isolates of C. cassiicola, but the grouping was not indicate the country of origin and the host species of isolates. Geographic and host rubber clones origin of the isolates isolated affect the ability of the virulence and diversity of ITS-rDNA sequences of C. cassiicola isolates were analyzed. Compared to geographic, the influence of the host rubber clones were more clearly to the virulence level of isolates. Analysis of the diversity of ITS-rDNA sequences showed that there were three points Single Nucletide Polymorphism (SNPs) on the 23 of C. Cassiicola isolates analyzed that separated isolates into 5 different haplotypes, and most of the isolates belonged to the haplotype 1 . There was a relationship between the ITS-rDNA sequences with the ability of virulence, which changes of the base at the SNPs point caused change of the isolates virulence level.

\section{ACKNOWLEDGMENTS}

The authors would like to acknowledge Dr. Thomas Wijaya for his revision of the English and thankfull for the financial support of the Indonesian Rubber Research Institute for this research.

\section{Author's contributions}

This manuscript is part of the PhD Dissertation (Plant Breeding and Biotechnology) of first author advised by all co-author. Fetrina Oktavia was responsible for isolation of isolates from field, extraction of DNA, PCR analysis, data analysis and wrote of the manuscript. Kuswanhadi, Widodo, Diny Dinarti and Sudarsono were responsible for supervise data analysis and processing of the manuscript.

\section{REFERENCES}

Akpaja, E., D. Omorogbe and N. Nwogu. 2015. Field and in-vitro studies on Corynespora leaf fall disease of Hevea brasiliensis in Nigeria. Br. Microb. Res. J. 7: 322-328.

Atan, S. and N. Hamid. 2003. Differentiating races of Corynespora cassiicola using RAPD and internal transcribed spacer markers. J. Rubber Res. 6: 58-64.

Bandelt, H. J., P. Forster and A. Rohl. 1999. Median joining networks for inferring intraspecific phylogenies. Mol. Biol. Evol. 6: 37-47.

Breton, F., C. Sanier and J. D'Auzac. 2000. Role of Cassiicolline. A host-selective toxin. in pathogenicity of Corynespora cassiicola. Causal agent of a leaf fall disease of Hevea. J. Rubber Res. 3: 
115-128.

Cutrim, F. and G. Silva. 2003. Pathogenicity of Corynespora cassiicola to different plant species. Phytopathology. 28: 103-193.

de Lamotte, F., M. P. Duviau, C. Sanier, R. Thai, J. Poncet, D. Bieysse, F. Breton and V. Pujade-Renaud. 2007. Purification and characterization of Cassiicollin toxin produced by Corynespora cassiicola causal agent of the leaf fall disease of rubber tree. J. Chrom. 849: 357-362.

Déon, M., A. Scomparin, A. Tixier, C. R. Mattos, T. Leroy, M. Seguin, P. Roeckel-Drevet and V. Pujade-Renaud. 2012a. First characterization of endophytic Corynespora cassiicola isolates with variant Cassiicolline genes recovered from rubber trees in Brazil. Fungal Divers. 54: 87-99.

Déon, M., Y. Bourré, S. Gimenez, A. Berger, D. Bieysse, F. de Lamotte, J. Poncet, V. Roussel, F. Bonnot, G. Oliver, J. Franchel, M. Seguin, T. Leroy, P. Roeckel-Drevet and V. Pujade-Renaud. 2012b. Characterization of a Cassiicolline-encoding gene from Corynespora cassiicola pathogen of rubber tree (Hevea brasiliensis). Plant Sci. 185-186: 227-237.

Déon, M., B. Fumanal, S. Gimenez, D. Bieysse, R. R. Oliveira, S. S. Shuib, F. Breton, S. Elumalai, J. B. Vida, M. Seguin, T. Leroy, P. Roeckel-Drevet and V. Pujade-Renaud. 2014. Diversity of the Cassiicolline gene in Corynespora cassiicola and relation with the pathogenicity in Hevea brasiliensis. Fungal Biol. 118: 32-47.

Dixon, L. J., R. L. Schlub, K. Pernezny, and L. E. Datnoff. 2009. Host specialization and phylogenetic diversity of Corynespora cassiicola. Phytopathology. 99: 1015-1027.

Fairuzah, Z., B. Setyawan and T. R. Febbyanti. 2009. Resistance and susceptibility of recomendation and promising rubber clones to Corynespora cassiicola isolates. In: Proceedings of the National Breeding Seminar. Publisher Indonesian Rubber Institute, Indonesia. p269-275.

Farr, D. and A. Rossman. 2015. Fungal Databases, Systematic Mycology and Microbiology Laboratory, ARS, USDA. Available from: https://www.nt.ars-grin.gov/fungaldatabases. [Last accessed on 2015 Dec 07].

Fernando, T., C. Jayasinghe, R. Wijesundera and D. Siriwardana. 2009. Variability of hevea isolates of Corynespora cassiicola from Sri Lanka. J. Plant Dis. Prot. 116: 115-117.

Fernando T. H. P. S., C. K. Jayasinghe, R. L. C. Wijesundera, W. P. K. Silva and E. A. D. N. Nishantha. 2010. Evaluation of screening methods against Corynespora leaf fall disease of rubber (Hevea brasiliensis). J. Plant Dis. Prot. 117: 24-29.

Fernando, T., C. Jayasinghe, R. Wijesundera and D. Siriwardane. 2012. Some factors affecting in vitro production, germination and viability of conidia of Corynespora cassiicola from Hevea brasiliensis. J. Nat. Sci. Sri Lanka. 40: 241-249.

Furukawa, T., K. Ushiyama and K. Kishi. 2008. Corynespora leaf spot of scarlet sage caused by Corynespora cassiicola. J. Genet. Plant Pathol. 4: 117-119.

Ganley, A. and T. Kobayashi. 2007. Highly efficient concerted evolution in the ribosomal DNA repeats: Total rDNA repeat variation evealed by whole-genome shotgun sequence data. Genet. Res. 17: 184-191.

Gazis, R., S. Rehner and P. Chaverri. 2011. Species delimitation in fungal endophyte diversity studies and its implications in ecological and biogeographic inferences. Mol. Ecol. 20: 3001-3013.

Glass, D., N. Takebayashi, L. Olson and D. Taylor. 2013. Evaluation of the authenticity of a highly novel environmental sequence from boreal forest soil using ribosomal RNA secondary structure modeling. Mol. Physiol. Evol. 67: 234-245.

Glass, N. and G. Donaldson. 1995. Development of primer sets designed for use with the PCR to amplify conserved genes from filamentous ascomycetes. Appl. Environ. Microbiol. 61: 13231330.

Harrington, T., M. Kazmi, A. Al-Sadi and S. Ismail. 2014. Intraspecific and intragenomic variability of ITS rDNA sequences reveals taxonomic problems in Ceratocytsis fimbriata sensu stricto. Mycologia. 106: 224-242.

Hieu, N., N. Nghia, V. Chi and P. Dung. 2014. Genetic diversity and pathogenicity of Corynespora cassiicola isolates from rubber trees and other hosts in Vietnam. J. Rubber Res. 17: 187-202.

Hinrikson, H., S. Hurst, T. Lott, D. Warnock and C. Morrisson. 2005. Assessment of ribosomal large-subunit D1-D2. Internal transcribed spacer 1 . And internal transcribed spacer 2 regions as targets for molecular identification of medically important Aspergillus species. J. Clin. Microb. 43: 2092-2103.

Isabel, N., J. Beaulieu, P. Theriault and J. Bousquet. 1999. Direct evidence for biased gene diversity estimates from dominant random amplified polymorphic DNA (RAPD) fingerprints. Mol. Ecol. 8: 477-482.

Katoch, A., C. S. Prabhakar and P. N. Sharma. 2015. Metageographic population analysis of Colletotrichum truncatum associated with chili fruit rot and other hosts using ITS region nucleotide sequences. J. Plant Biochem. Biotechnol. 25: 64-72.

Munir, M., H. Suryaningtyas, A. Situmorang and T. R. Febbyanti. 2009. Resistance of rubber clones IRR series 100 to Corynespora and Colletotrichum leaf fall disease. In: Proceedings of the National Breeding Seminar. Publisher Indonesian Rubber Institute, Indonesia. pp262-268.

Munir, M., H. Suryaningtyas and Kuswanhadi. 2011. Genetic variability analysis of Corynespora cassiicola (Berk and Curt) Wei. Isolates in Indonesia using ISSR. Indones. J. Nat. Rubber Res. 30: 86-99.

Murali, T., T. Suryanarayanan and R. Geeta. 2006. Endophytic Phomopsis species: Host range and implications for diversity estimates. Can. J. Microb. 57: 673-680.

Nghia, N., J. Kadir, E. Sunderasan, M. Abdullah, A. Malik and S. Napis. 2008. Morphological and inter simple sequence repeat (ISSR) markers analyses of Corynespora cassiicola isolates from rubber plantations in Malaysia. Mycopathologia. 166: 189201.

Nghia, N., J. Kadir, E. Sunderasan, M. Abdullah, A. Malik and S. Napis. 2010. Intraspecific variability of Corynespora cassiicola inferred from single nucletide polymorphisms in ITS region of ribosomal DNA. J. Rubber Res. 13: 257-264.

Nilsson, H., E. Kristiansson, M. Ryberg, N. Hallenbergand and K. Larsson. 2008. Intraspecific ITS variability in the kingdom fungi as expressed in the international sequence databases and it's implications for molecular species identification. Evol. Bioinformatics. 4: 193-201.

Nilsson, R., M. Ryberg, K. Abarenkov, E. Sjokvist and E. Kristiansson. 2009. The ITS region as a target for characterization of fungal communities using emerging sequencing technologies. FEMS Microbiol. Lett. 296: 97-101.

Ogbebor, O.N. 2010. The status of three common leaf disease of Para rubber in Nigeria. J. Plant Sci. 6: 567-570.

Oktavia, F., M. Munir, H. Suryaningtyas and K. Kuswanhadi. 2011. Characterization of DNA finger printing of Corynespora cassiicola isolates from varians regions of rubber plantation. Indones. J. Nat. Rubber Res. 29: 118-128.

Othman, R. 2013. Development of High Yielding Disease Resistance Clones. IRRDB Agronomy Workshop, Indonesia.

Oubraim, S., H. S. Moulay and H. B. Lazrek. 2016. A relationship 
between bayoud disease severity and toxin susceptibility of date palm cultivars. Emir. J. Food Agric. 28: 45-51.

Qi, Y. X., X. Zhang, J. J. Pu, X. M. Liu, Y. Lu, H. Zhang, H. Q. Zhang, Y. C. LV and Y. X. Xie. 2011. Morphological and molecular analysis of genetic variability within isolates of Corynespora cassiicola from different hosts. Eur. J. Plant Pathol. 130: 83-95.

Rampersad, S. N., D. Perez-Brito, C. Torres-Calzada, R. TapiaTussell and C. V. Carrington. 2013. Genetic structure and demographic history of Colletotrichum gloeosporioides sensu lato and C. truncatum isolates from Trinidad and Mexico. BMC Evol. Biol. 13: 1-17.

Romruensukharom, P., S. Tragoonrung, A. Vanavichit and T. Toojinda. 2005. Genetic variability of Corynespora cassiicola populations in Thailand. J. Rubber Res. 8: 38-49.

Saha, T., A. Kumar, B. Roy, M. Ravindran, A. Joseph, C. K. Jacob, M. A. Nazeer, K. Sreedharan, K. Vinod and B. Chulaki. 2002. Molecular characterisation of fungal pathogens causing leaf diseases in rubber (Hevea brasiliensis). In: Proceeding of the 15th Plantation Crops Symposium Placrosym XV. India. p195-203.

Savita-Virk, G. S. and A. Nagpal. 2011. In vitro selection of calli of Citrus jambhiri Lush. For tolerance to culture filtrate of Phytophthora parasitica and their regeneration. Physiol. Mol. Biol. Plants. 17: 41-47.

Schoch, C., K. Seifert, S. Huhndorf, V. Robert, J. Spouge, C. Levesque, W. Chen and F. B. Consortium. 2012. Nuclear ribosomal internal transcribed spacer (ITS) region as a universal DNA barcode marker for fungi. PNAS. 109: 6241-6246.

Shimomoto, Y., R. Adachi, Y. Morita, K. Yano, A. Kiba, Y. Hikichi and S. Takeuchi. 2008. Corynespora blight of sweet pepper (Capsicum annuum) caused by Corynespora cassiicola (Berk. and Curt.) Wei. J. Gen. Plant Pathol. 74: 335-337.

Shimomoto, Y., T. Sato, H. Hojo, Y. Morita, S. Takeuchi, H. Mizumoto, A. Kiba and Y. Hikichi. 2011. Pathogenic and genetic variation among isolates of Corynespora cassiicola in Japan. Plant Pathol. 60: 253-260.

Shuib, S., M. Deon, M. M. Mahyuddin, A. Izhar, B. Fumanal, E. Sunderasan and V. Pujade-Renaud. 2015. Cassiicolline genes among Corynespora cassiicola isolates from rubber plantations in Malaysia. J. Rubber Res. 18: 6241-6246.

Silva, W. P. K., E. H. Karunanayake, R. L. C. Wijesundera and U. M. S. Priyanka. 2003. Genetic variation in Corynespora cassiicola: A possible relationship between host origin and virulence. Mycol. Res. 107: 567-571.

Situmorang, A. 2002. Spreading of the Corynespora Leaf Fall Disease, Virulence and Genetic of Corynespora cassiicola were Collected from Rubber Plantation in Indonesia, Ph.D. Dissertation. Bogor Agricultural University, Indonesia.

Situmorang, A., M. Sinaga, R. Suseno, S. H. Siswanto and A. Darussamin. 2007. Spreading of Corynespora leaf fall disease in the Indonesian rubber plantation. Indon. J. Nat. Rubber Res. 25: 76-82.

Smith, L. and R. Schlub. 2005. Foliar fungi on weeds of Guam and the potential for Corynespora cassiicola as a bioherbicide for Stachytarpheta jamaicensis. (Abstract). Phytopathology. 95: S93.

Tran, D. M., A. Clement-Demange, M. Deon, D. Garcia, V. Le Guen, A. Clement-Vidal, M. Souahoro, A. Masson, P. Label, M. T. Le and V. Pujade-Renaud. 2016. Genetic determinism of sensitivity to Corynespora cassiicola exudates in rubber tree (Hevea brasiliensis). PLoS One. 11: e0162807.

U'ren, J., J. Dalling, R. Gallery, D. Maddison, E. Davis, C. Gibson and A. Arnold. 2009. Diversity and evolutionary origins of fungi associated with seeds of a Neotropical pioneer tree: A case study for analyzing fungal environmental samples. Mycol. Res. 113: 432-449.

White, T. J., T. Bruns, S. Lee and J. Taylor. 1990. Amplification and direct sequencing of fungal ribosomal RNA genes for phylogenetics. In: Innis, M. A., D. Gelland, J. J. Sninsky and T. J. White (Eds.), PCR Protocols: A Guide to Methods and Applications. Academic Press, New York. pp315-322.

Yusnita, Y., W. Widodo and S. Sudarsono. 2009. In vitro selection of peanut somatic embryos on medium containing culture filtrate of Sclerotium rolfsii and planlet regeneration. Hayati. J. Biosci. 12: $50-56$ 